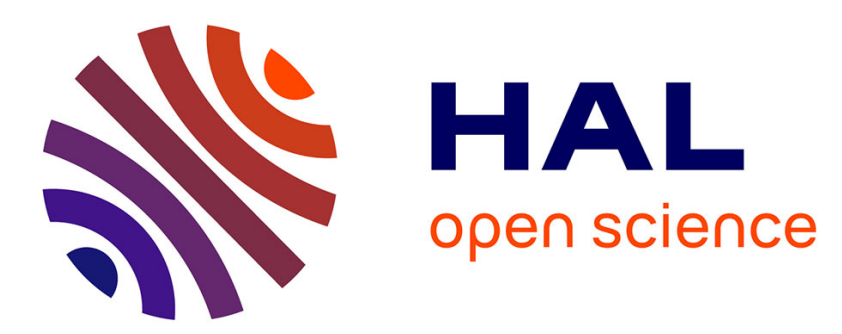

\title{
High resolution micromill sampling for analysis of fish otoliths by ICP-MS: effects of sampling and specimen preparation on trace element fingerprints
}

\author{
Zikri Arslan, David H. Secor
}

\section{- To cite this version:}

Zikri Arslan, David H. Secor. High resolution micromill sampling for analysis of fish otoliths by ICPMS: effects of sampling and specimen preparation on trace element fingerprints. Marine Environmental Research, 2008, 66 (3), pp.364. 10.1016/j.marenvres.2008.05.010 . hal-00563037

\section{HAL Id: hal-00563037 https://hal.science/hal-00563037}

Submitted on 4 Feb 2011

HAL is a multi-disciplinary open access archive for the deposit and dissemination of scientific research documents, whether they are published or not. The documents may come from teaching and research institutions in France or abroad, or from public or private research centers.
L'archive ouverte pluridisciplinaire HAL, est destinée au dépôt et à la diffusion de documents scientifiques de niveau recherche, publiés ou non, émanant des établissements d'enseignement et de recherche français ou étrangers, des laboratoires publics ou privés. 


\section{Accepted Manuscript}

High resolution micromill sampling for analysis of fish otoliths by ICP-MS: effects of sampling and specimen preparation on trace element fingerprints

Zikri Arslan, David H. Secor

PII: S0141-1136(08)00164-5

DOI: 10.1016/j.marenvres.2008.05.010

Reference: MERE 3262

To appear in: Marine Environmental Research

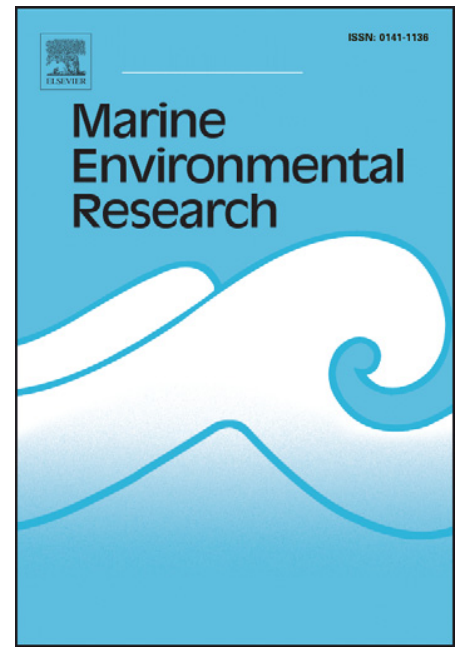

Received Date: $\quad 24$ September 2007

Revised Date: 28 May 2008

Accepted Date: $\quad 29$ May 2008

Please cite this article as: Arslan, Z., Secor, D.H., High resolution micromill sampling for analysis of fish otoliths by ICP-MS: effects of sampling and specimen preparation on trace element fingerprints, Marine Environmental Research (2008), doi: 10.1016/j.marenvres.2008.05.010

This is a PDF file of an unedited manuscript that has been accepted for publication. As a service to our customers we are providing this early version of the manuscript. The manuscript will undergo copyediting, typesetting, and review of the resulting proof before it is published in its final form. Please note that during the production process errors may be discovered which could affect the content, and all legal disclaimers that apply to the journal pertain. 
High resolution micromill sampling for analysis of fish otoliths by ICP-MS: effects of sampling and specimen preparation on trace element fingerprints

\author{
Zikri Arslan $^{\text {a,* }}$, David H. Secor ${ }^{\text {b }}$
}

${ }^{a}$ Jackson State University, Department of Chemistry, P.O. Box 17910, Jackson, MS 39217 USA

${ }^{b}$ Chesapeake Biological Laboratory, University of Maryland Center for Environmental Science, P.O. Box 38, Solomons, MD 20688 USA

*Corresponding author. Tel.: +1 (601) 979-2072; fax: +1 (601) 979-3674

E-mail address: zikri.arslan@jsums.edu (Z. Arslan) 


\section{Abstract}

Otoliths are calcified structures in the head of fish that record environmental information about fish's life history. Gathering the elemental information from the core of an otolith corresponding to the juvenile period of fish's life is critical to discriminate the adult fish to their natal habitats reliably. A high resolution micromill has been used to isolate the otolith core from a whole otolith for elemental analysis. The effects of micromilling procedures (e.g., sectioning, embedding and drilling) on contamination to otolith trace element levels were examined using paired blackfin tuna (Thunnus atlanticus) otoliths. Otoliths were decontaminated by dilute hydrogen peroxide and nitric acid throughout to remove surface contamination. A preconcentration procedure was used to determine the trace elements from the small core material by ICP-MS. It was found that micromilling procedures introduce significant contamination to otoliths, especially for $\mathrm{Al}, \mathrm{Cu}, \mathrm{Pb}$ and $\mathrm{Zn}$. The sectioning procedure caused significant contamination for $\mathrm{Co}$ and $\mathrm{Cu}$, while the embedding procedure resulted in contamination for nearly all trace elements (Al, Cd, Co, Cu, Ga, Mn, Ni, Pb, V, and $\mathrm{Zn}$ ). The combined sectioning, embedding and drilling procedure also resulted in contamination for most trace elements. Despite the contamination across all procedural steps, the decontamination procedure effectively removed the surface contamination with the exception of $\mathrm{Pb}$ and $\mathrm{Zn}$. Bias (e.g., residual contamination) on $\mathrm{Pb}$ was small in comparison to overall concentration of $\mathrm{Pb}$ expected to occur in fish otoliths, therefore, its effect may be minor in discriminating individuals. Bias on $\mathrm{Zn}$ was larger that could limit its application in discriminating individuals.

Keywords: Blackfin tuna; Otolith chemistry; Trace element; Micromill sampling; ICP-MS 


\section{Introduction}

Otolith chemical composition has been a particularly valuable tool for marine and fishery ecologists in understanding the spatial ecology of marine fish (Edmonds et al., 1991, 1992; Campana and Thorrold, 2001; Thorrold et al., 2001; Gillanders, 2002; Kraus and Secor, 2005). A principal application of otolith microchemistry is to assign widely distributed adults to their natal nursery habitats using otoliths as birth certificates (Secor, 2004) or natural tags (Campana, 2000). Classification accuracy using otolith microchemistry is moderate and often ranges between 60 and 80\% (Forrester and Swearer, 2002; Secor et al., 2002; Rooker et al., 2003; Patterson et al., 2004; Arslan and Secor, 2005; Swan et al., 2006). Such classification rates show promise, but are often insufficient for intended applications. Curtailed classifications are in part due to analytical issues associated with the quadrupole inductively coupled plasma mass spectrometry (ICP-MS) which is the most commonly utilized technique for otolith microchemical analysis. ICP-MS is advantageous because of its high sensitivity, multi-element analysis capability, and high sample throughput (Campana, 1999; Thresher, 1999). For trace elements at picogram or nanogram per gram levels in otoliths, accurate determination is, however, hindered by insufficient detection limits, contamination, and spectral and non-spectral interferences from otolith matrix. Separation/preconcentration approaches have proved to be powerful means to overcome such issues in analysis of fish otolith by ICP-MS (Arslan and Paulson, 2002, 2003; Arslan and Secor, 2005).

Classifying adult fish to natal habitats requires isolating the otolith material associated with juvenile stage of the fish's life, so-called the “core” of otolith. Probe-based techniques, including laser ablation ICP-MS, electron probe microanalysis (EPMA) and micro-proton induced X-ray emission (micro-PIXE) are commonly used. Among these techniques, laser 
ablation ICP-MS is a powerful technique as it combines spot ablation feature of laser with high sensitivity of ICP-MS (Thresher, 1999; Thorrold et al., 2001; Arai and Hirata, 2006; Aria et al., 2007). However, laser ablation ICP-MS suffers from issues of calibration, ablation, fractionation and sample transport. Other techniques (e.g., EPMA and micro-PIXE) lack the sensitivity required for accurate detection of trace elements, such as $\mathrm{Cd}, \mathrm{Cu}, \mathrm{Pb}$ and Zn, which are usually present in otoliths at sub-ng/g levels (Thresher, 1999, Arai and Hirata, 2006). As an alternative, high resolution micromilling affords powerful tool to extract the temporal information from otoliths for quantitative analysis by conventional bulk solution ICP-MS (Wurster et al., 1999).

While isolation of the otolith core is now feasible, accurate detection of the small differences in trace element concentrations from tiny otolith core is limited by the detection capability of ICP-MS and contamination issues during the core isolation process. Micromill sampling has been successfully applied to the measurement of stable isotopes of $\delta^{13} \mathrm{C}$ and $\delta^{18} \mathrm{O}$ from otoliths of various fish (Hoie et al., 2004; Rooker and Secor, 2004; Hoie and Folkvord, 2006), but there is no information to date regarding the performance of the technique for trace elements. In this study, we utilized a high-resolution micromill sampling technique and analyzed the otoliths of blackfin tuna (Thunnus atlanticus) for trace transition elements and heavy metals by ICP-MS with the aid of a solid phase preconcentration method. The objective of the study was a) to investigate the contamination, accuracy and precision issues to otolith trace element measures from micromilling protocols, and consequently b) to determine the utility of the elemental information gathered from micromilled (cored) otolith to discriminate among individuals. 


\section{Materials and methods}

\subsection{Otolith samples}

Sagittal otolith pairs were extracted from blackfin tuna (69-84 curved fork length) collected by angling from Texas Gulf of Mexico waters during February-March, 2002. No effort was made to use clean procedures in extraction. Adhering tissue was removed in the field and otoliths were stored dry until further processing.

\subsection{Core isolation procedure}

Isolation of the core from otolith was performed using a Mercantek Micromill which consists of a microscope and imaging system, an automated stage controlled precisely by computer software, and a tungsten milling drill embedded in the nose piece of the microscope. Prior to milling, sagittal otoliths were first embedded in epoxy resin and then sectioned using a low speed Isomet saw to obtain a $2 \mathrm{~mm}$ transverse section through the core. This section was glued to a thin plastic block with thermoplastic glue and then attached to the microscope stage of the micromill system. The intervening plastic block beneath the sectioned otolith allowed the drill to completely transverse the otolith without striking the stage. Following attachment to the microscope stage, the portion of the otolith corresponding to the first year of life was identified (via measurements from sectioned otoliths of yearling bluefin tuna), and the drill path was programmed into the micromill system. Approximately 20 passes were made at 30 microns depth per path to completely isolate the core of the 
otolith (Fig. 1). The cored material (a prism of intact material) was then removed carefully from the section using forceps and stored in a plastic vial for analysis.

\subsection{Otolith decontamination procedure}

According to trial specifications (Fig. 2), sagittal otoliths were rigorously decontaminated to remove surface contamination. This was performed by sequential treatment of pairs separately with $\mathrm{H}_{2} \mathrm{O}_{2}$ and $\mathrm{HNO}_{3}$. First, otoliths were soaked in deionized water to hydrate the surface of the sample. Next the otoliths were soaked in $3 \% \mathrm{H}_{2} \mathrm{O}_{2}$ for 5 min to dissolve any biological residue. They were then immersed for $5 \mathrm{~min}$ in $1 \% \mathrm{v} / \mathrm{v} \mathrm{HNO}_{3}$ acid to remove surface contamination, and then flooded with deionized water for 5 min to remove the acid. Finally, they were dried under a Class 100 laminar flow hood, weighed to the nearest 0.01 mg, and stored in plastic vials.

\subsection{Tests of contamination from micromilling procedures}

The micromilling procedure to isolate the otolith’s core involves multiple steps (e.g., sectioning, embedding and milling) that increase the risk of contamination on trace elements. A series of carefully designed experiments (Fig. 2) were carried out on paired otoliths to test the magnitude of contamination from individual treatments and to examine the ability of the otolith decontamination procedure to remove surface contamination prior to instrumental analysis. 


\subsubsection{Test of otolith decontamination procedure}

In this experiment, one otolith of each pair was deliberately contaminated by immersing in a multi-element solution that contained $1000 \mathrm{ng} / \mathrm{mL}(\mathrm{ppb})$ of $\mathrm{Cu}, \mathrm{Mn}$ and $\mathrm{Zn}$, and 10 ng/mL (ppb) of Al, Bi, Cd, Co, Ga, Mn, Ni, Pb and V. These levels were about two to three orders of magnitude higher than the expected concentrations of the metals in the otoliths. After immersing for $2 \mathrm{~min}$, the otoliths were removed from the solution, dried overnight and then experimentally decontaminated with $3 \% \mathrm{H}_{2} \mathrm{O}_{2}$ and $1 \% \mathrm{HNO}_{3}$ as described above. Otoliths were then dissolved and analyzed for a suite of trace elements by ICP-MS. The levels of the metals from the contaminated otolith were compared to those from the second (control) otolith which received only the cleaning procedure. The results from this test permitted us to determine whether the experimental cleaning procedure is in fact removing surface contamination. This trial was conducted with 11 pairs of otoliths.

\subsubsection{Test of contamination from sectioning and embedding}

Micromill sampling of the core was achieved via first embedding the otolith in a resin, then sectioning and finally drilling the sectioned piece by a tungsten drill bit to extract the

core. Embedding in epoxy glue was necessary to stabilize the otolith under the drill bit for precise operation, while sectioning was required to expose the area for drilling.

To determine the contamination from the metallurgical saw, blackfin tuna otoliths $(n=7)$ were without embedding held against a rotating saw so that a transverse cut was made halfway through the core section. This otolith was compared to its pair without decontaminating the control and sectioned otolith. The efficiency of the decontamination protocol to remove 
surface contamination from sawing was tested in a separate trial of blackfin tuna otoliths $(n=7)$. In this case, both sectioned otolith and its pair (control) were decontaminated with 3\% $\mathrm{H}_{2} \mathrm{O}_{2}$ and $1 \% \mathrm{HNO}_{3}$ protocol.

To test the contamination from embedding process, juvenile blackfin tuna otoliths $(n=7)$ were partially embedded in epoxy resin; the other half was exposed to air. Once the resin completely hardened, the otoliths were displaced out of the resin block by drop-wise treatments with $10 \% \mathrm{HNO}_{3}$. The elemental signals from these otoliths were compared with those from their pairs which had not been embedded. In this experiment, no post-treatment decontamination was feasible since the acid treatment to remove the embedded otolith out of the block resulted in dissolution of entire otolith.

\subsubsection{Test of contamination from coring}

First, the isolated core was compared to its pair without employing decontamination procedure. For another 7 pairs of otoliths, isolated core of the otolith and its pair were decontaminated as described above to determine if decontamination procedure was effective in removing the contaminants. In these tests, it was assumed that the segment isolated represented the entire growth history of the yearling blackfin tuna.

\subsection{Elemental analysis of otolith samples}

Elemental analysis of otolith samples was carried out by using a Perkin-Elmer Sciex Elan $^{\circledR} 5000$ ICP-MS instrument (Norwalk, CT, USA) equipped with cross-flow nebulizer, a double-pass spray chamber, a quartz ICP torch, removable alumina injector, platinum 
sampler and skimmer cones, and single-channel mass flow controller. The instrument was tuned daily for highest sensitivity with optimum levels of oxides $\left(\mathrm{CeO}^{+} / \mathrm{Ce}^{+}<3 \%\right)$ and doubly charge ions $\left(\mathrm{Ba}^{++} / \mathrm{Ba}^{+}<2 \%\right)$ by a test solution containing $10 \mathrm{ng} / \mathrm{mL}$ of $\mathrm{Ba}, \mathrm{Ce}, \mathrm{Mg}$, $\mathrm{Rh}$ and $\mathrm{Pb}$. Solutions were introduced to the spectrometer by using a Perkin Elmer FIAS-400 unit equipped with a five port rotary flow injection valve. The operating conditions of the ICP-MS instruments are given in Table 1.

\subsubsection{Otolith dissolution procedure}

For ICP-MS analysis, otolith pairs, each (right and left) were separately digested in $1 \mathrm{~mL}$ concentrated $\mathrm{HNO}_{3}$ on a hot plate. The contents were heated to near dryness and then an additional $0.5 \mathrm{~mL} \mathrm{HNO}_{3}$ was added onto the residue to completely destroy organic components. The acidic solution was heated again to dryness to get rid of excess acid. Then, the residue was dissolved in $1 \mathrm{~mL}$ deionized water and heated to dryness similarly. This last step was repeated twice to eliminate the concentrated acid vapors. In the end, the residue was dissolved and diluted with $0.1 \% \mathrm{v} / \mathrm{v} \mathrm{HNO}_{3}(\mathrm{pH} \sim 1.80)$ to $10 \mathrm{~mL}$ in acid washed 15-mL polypropylene test tubes. For quality control purpose, a fish otolith certified reference material (CRM No. 22) from the National Institute of Environmental Studies (NIES) of Japan was also dissolved similarly with the blackfin tuna otoliths. The CRM is prepared from sagittal otoliths of emperor snapper (Lutjanus sebae). Approximately 50-60 mg sample was first digested with $1 \mathrm{~mL} \mathrm{HNO}_{3}$ in a teflon beaker to near dryness followed by additional 1 $\mathrm{mL} \mathrm{HNO}_{3}$. All evaporations and dilutions were made as for the blackfin tuna otoliths. For blanks, $1.5 \mathrm{~mL} \mathrm{HNO}_{3}$ was heated as for the otoliths and then diluted to $10 \mathrm{~mL}$. 


\subsubsection{Preconcentration procedure}

The main goal of this study was to examine the effects of micromilling procedures on elemental signals in otoliths, specifically those of $\mathrm{Al}, \mathrm{Cu}, \mathrm{Mn}, \mathrm{Ni}, \mathrm{Pb}$ and $\mathrm{Zn}$ that are highly prone to contamination issues from sampling protocols under ambient conditions. These elements are also present in fish otoliths at significantly lower concentrations than alkaline and alkaline earth elements, such as Ba, Mg, Na and Sr (Thresher, 1999; Arslan and Paulson, 2002; Arslan and Secor, 2005; Arai et al., 2007). For accurate measurement, we opted for a preconcentration strategy to improve ICP-MS signals and to eliminate the interferences from the otolith calcium matrix. . Because the preconcentration column did not retain alkali and alkaline earth elements, Ba, Mg and Sr were not measured in this study.

The preconcentration procedure was described elsewhere (Arslan and Paulson 2002; Arslan and Secor 2005). In brief, a minicolumn of Toyopearl AF-Chelate 650M (Tosohaas); an iminodiacetate backbone chelating resin was used for the preconcentration. This resin forms metal-chelates with a suite of trace elements in a $\mathrm{pH}$ range from 4.9 to 9 . The preconcentration column consisted of 1-cm long resin holder (85 $\mu$ l inner volume) which was push-fit into 2-cm long outer body. The two ends were closed with trace element-free glass frits and then cleaned by passing $5 \% \mathrm{HNO}_{3}$. The otolith solution acidified to $0.1 \% \mathrm{HNO}_{3}$ was mixed on-line with ammonium acetate/ammonium hydroxide buffer solution (pH 9.6) and loaded onto the column for $1 \mathrm{~min}$ at $3.2 \mathrm{~mL} / \mathrm{min}$ by FIAS-400 system. The load $\mathrm{pH}$ was between $\mathrm{pH} 4.9$ and 5.2 allowing the retention of the elements of interest on the column with minimum amounts of calcium. Lower end of $\mathrm{pH}$ range $(\mathrm{pH} 4.9$ - 9) was preferred as it minimized the retention of Ca in the column. The column was washed with deionized water 
to get rid of residual calcium and then the trace elements retained were transported to the ICP-MS spectrometer by passing $3 \% \mathrm{HNO}_{3}$ through the column. The elemental recoveries ranged between $88 \%$ for $\mathrm{Ga}$ and $102 \%$ for $\mathrm{Pb}$ and $\mathrm{Zn}$ based on the measurements with spiked otolith solution (Arslan and Paulson, 2002). Internal standard $\left({ }^{103} \mathrm{Rh}\right)$ was added to the $3 \%$ $\mathrm{HNO}_{3}$ eluent to correct for the effects of instrumental sensitivity changes on the ion signals. Namely, the elemental signals were normalized to that of Rh. Manganese (Mn) was analyzed separately at $\mathrm{pH}$ of 8.2-8.5; therefore, the remaining solution in the test tube was diluted twofold (e.g., final acidity $0.05 \% \mathrm{HNO}_{3}$ ) and reanalyzed for $\mathrm{Mn}$. Calibration standards were in $0.1 \% \mathrm{HNO}_{3}(0.05 \%$ for $\mathrm{Mn})$.

\section{Results}

\subsection{Analytical performance and elemental concentrations in blackfin tuna otoliths}

For all elements of interest, concentrations were within the range of the values reported elsewhere (Table 2; Fig. 3; Yoshinaga et al., 1999; Arslan and Paulson, 2002). Multiple isotopes of the poly-isotopic elements were simultaneously analyzed and the results were provided for most-interference free isotopes (e.g., ${ }^{62} \mathrm{Ni}$ among ${ }^{58} \mathrm{Ni},{ }^{60} \mathrm{Ni}$ and ${ }^{62} \mathrm{Ni}$ ). Detection limits were virtually identical to those reported previously (Arslan and Paulson 2002) and were all above the concentrations of the elements in solutions of otolith CRM (Table 2) and blackfin tuna otoliths (Fig. 3A). Replicate decontamination procedures between otolith pairs indicated a precision of measurement that ranged between 5 and 20\% among elements (Fig. 3B). 


\subsection{Otolith decontamination}

Paired comparisons between control and treatment otoliths (deliberately contaminated, then cleaned) indicated that otoliths could be effectively decontaminated (Fig. 3B). Comparisons for blackfin showed insignificant differences (paired t-test; $\mathrm{n}=11$ pairs; $\mathrm{p}>0.1$ ) for $\mathrm{Al}, \mathrm{Bi}, \mathrm{Cd}, \mathrm{Co}, \mathrm{Mn}, \mathrm{Ni}, \mathrm{Pb}, \mathrm{V}$, and $\mathrm{Zn}$. Cu, levels in contaminated otoliths were higher as a result of deliberate contamination (mean=18.5 ng/g increase; $\mathrm{p}<0.001$ ). Across all elements, paired differences did not differ significantly from zero (paired t-test; $n=121$; mean=7.96; ng g $^{-1} ; \mathrm{p}=0.41$ ). Mean bias between replicate measures was as follows: $\mathrm{Al}=11 \%$, $\mathrm{Bi}=15 \%, \mathrm{Cd}=17 \%, \mathrm{Co}=12 \%, \mathrm{Cu}=10 \%, \mathrm{Ga}=26 \%, \mathrm{Mn}=11 \%, \mathrm{Ni}=16 \%, \mathrm{~Pb}=14 \%, \mathrm{~V}=8 \%$ and $\mathrm{Zn}=6 \%$.

\subsection{Sectioning}

The sectioning procedure caused significant contamination for Co and $\mathrm{Cu}$ (Fig. 4). Sectioned otoliths showed significantly higher $\mathrm{Cu}$ (paired t-test; n=7; mean=1716 ng g ${ }^{-1}$; $\mathrm{p}<0.001$ ), and marginally higher Co (paired t-test; $\mathrm{n}=7$; mean=14.0 $\mathrm{ng} \mathrm{g}^{-1} ; \mathrm{p}<0.06$ ). For other elements, differences in elemental concentrations for paired comparisons were less than $10 \%$, with the exception of $\mathrm{Pb}$ (median=18\%). The contamination on $\mathrm{Co}$ and $\mathrm{Cu}$ was effectively removed when sectioned otoliths were subsequently decontaminated (Fig. 4). The imprecision between sectioned and control otoliths for these elements did not deviate significantly from zero (paired t-test; $n=7$; Co: mean=0.07 ng g ${ }^{-1} ; \mathrm{p}=0.66$; Cu: mean= -50.9 ng $\mathrm{g}^{-1} ; \mathrm{p}=0.33$ ). Only $\mathrm{Mn}$ deviated significantly (paired t-test; $\mathrm{n}=7$; mean=23.9 ng g g $^{-1}$ 
$\mathrm{p}=0.05$ ), but the mean level of imprecision (9.8\%) was within the level expected from replicate comparisons.

\subsection{Embedding}

Embedding contributed substantial contamination to otoliths for most trace elements analyzed. Significant differences were found between control and embedded pairs for Al, Cd, Co, Cu, Ga, Mn, Ni, Pb, and V (paired t-test; n=7; p<0.003; Fig. 5). Zn was marginally higher in embedded otoliths $(\mathrm{p}=0.09)$. Percent differences between elemental levels were substantial, particularly for $\mathrm{Cd}, \mathrm{Ni}, \mathrm{Pb}$, and V (e.g., over $800 \%$ imprecision). Given the high level of contamination, a second trial was made under different conditions where dissolution of the otoliths from the plastic embedding medium was carried out by using dilute acid without applying heat. However, the results of this trial were not different from that of the first trial. Substantial contamination was found particularly on $\mathrm{Al}, \mathrm{Cd}, \mathrm{Cu}, \mathrm{Mn}, \mathrm{Ni}, \mathrm{Pb}$, and $\mathrm{Zn}$.

Although we were able to establish the level of contamination due to embedding, it was not possible to test the effectiveness of the decontamination procedure following embedding. The embedded portion of the otolith could not be removed without fusing the entire otolith since the peripheral regions of otoliths were infiltrated with the plastic embedding medium. The embedding medium did not, however, fully infiltrate the otolith and thus the core region should not be affected by contamination. In this case, the effectiveness of the decontamination procedure could only be tested for the entire procedure (embedding, sectioning, and core removal) rather than the embedding step. 


\subsection{Coring}

The coring procedure contributed substantial contamination to otoliths for most transition and heavy metals (Fig. 6). Significant differences occurred between control and cored pairs for $\mathrm{Al}, \mathrm{Cd}, \mathrm{Co}, \mathrm{Cu}, \mathrm{Ni}, \mathrm{Pb}$, and $\mathrm{V}$ (paired t-test; $\mathrm{n}=7$; $\mathrm{p}<0.03$ ). Zn was marginally higher in cored otoliths $(\mathrm{p}=0.06)$. Percent differences were substantial that ranged between 100 to $10,000 \%$ due to contamination. Despite high levels of contamination from the milling procedure, the decontamination procedure on otolith cores effectively removed the surface contamination (Fig. 6). Only $\mathrm{Pb}$ and $\mathrm{Zn}$ showed higher levels in the cored otolith than in the control whole otolith (paired t-test; $\mathrm{n}=7$; $\mathrm{p}<0.03$ ), though the levels of $\mathrm{Zn}$ and $\mathrm{Pb}$ were respectively reduced 6- and 8-fold through decontamination. The residual contamination on $\mathrm{Pb}$ following the cleaning procedure $\left(\sim 8 \mathrm{ng} \mathrm{g}^{-1}\right)$ was substantially less than relevant concentrations ( $\sim 20$ to $100 \mathrm{ng} \mathrm{g}^{-1}$ ). Percent imprecision was considerably higher than duplicate imprecision levels (see Fig. 3 vs. Fig. 6), ranging over 30\% for Al (31\%), Cd (58\%), Co (70\%), Ga (76\%), Pb (60\%), V (35\%), and Zn (37\%). Thus, results suggest that coring introduced bias in addition to residual contamination. The most likely source of bias was how accurately the milled core volumetrically represented the whole otolith.

\section{Discussion}

\subsection{Effects of micromilling procedures}

Micromilling procedures are becoming more common in extracting otolith material from certain regions of fish otoliths (Hoie et al., 2004; Rooker and Secor, 2004; Hoie and Folkvord, 2006). In most instances, material is rasterred as powder by the micro-mill. We 
opted not to raster otoliths, because the resulting powder would in no way be decontaminated. Instead, the core was isolated by milling a complete perimeter around the core region. The resultant core was then dislodged from the section and decontaminated as it would for a whole otolith. The aim of this study was two-fold: (1) to develop a method to accurately extract the otolith fraction corresponding to the first year of life, (2) to examine the effectiveness of the decontamination procedure to alleviate the contamination issues through all steps of the process. Our main finding is that micromilling procedures introduce significant contamination to otolith trace element composition. This is not surprising given the sub-ng/g levels of these elements in otoliths and the presence of especially more common elements like $\mathrm{Al}, \mathrm{Cu}, \mathrm{Pb}$ and $\mathrm{Zn}$ in chemicals and materials that surface contamination may occur even under clean conditions.

The sectioning procedure caused significant contamination on $\mathrm{Co}$ and $\mathrm{Cu}$ levels, while the embedding procedure resulted in contamination for nearly all transition and heavy metals analyzed (Al, Cd, Co, Cu, Ga, Mn, Ni, Pb, V, and Zn) (Fig. 4). The combined sectioning, embedding and coring procedure also resulted in contamination for most elements (Fig. 6). Still, across all these procedural steps, the rigorous decontamination procedure with $\mathrm{H}_{2} \mathrm{O}_{2}$ and $\mathrm{HNO}_{3}$ effectively removed bias due to surface contamination with the exception of $\mathrm{Pb}$ and $\mathrm{Zn}$ (Fig. 6). Bias in $\mathrm{Pb}$ was small in comparison to overall concentration of $\mathrm{Pb}$ expected in fish otoliths, so its effect may be minor in discriminating individuals. Zn showed larger contamination which could limit its application in discriminating individuals at concentrations similar to those that are expected to occur in otoliths,

Paired comparisons of whole and cored otoliths showed greater bias than that expected from replicate comparisons of whole otoliths ( 20\%), ranging over 30\% for the majority of elements (Fig. 6). Although there was no bias (e.g., under- or over-representation of 
elements in the core), the reduced precision was likely due to non-homogeneity of material in the otolith and the manner in which the micromill extracted the material of the first year of life. Due to the peculiar butterfly shape of scombrid otoliths in transverse cross-section, we could only consistently apply a method that sampled half of the otolith section corresponding to the first year of life (Fig. 1). We sought to do this consistently with the aid of reference axes, but variations in the plane and thickness of the section and application of reference axes to the milling procedure would be expected to introduce some bias. Further, more fundamental bias may be introduced due to sampling only a portion (albeit a consistent portion) of the otolith volume corresponding to the first year of life.

\subsection{Analytical merits of preconcentration ICP-MS for micromill sampling}

The application of otolith microchemistry to discover natality depends upon a method that can isolate from adult otoliths the chemical composition associated with the first year. Probe-based methods, such as laser ablation, micro-PIXE, and electron microprobe have the capability of measuring certain elements in very small regions of the otolith corresponding to the larval and juvenile periods, but none can measure all alkaline, transition, and heavy elements that can be measured by solution-based techniques (e.g., ICP-MS). Reproducibility and calibration are the major obstacles for laser ablation ICP-MS in otolith microchemistry despite the advances in technology (Hoffmann et al., 1997; Koch and Günther, 2007). Detection limits are typically between 0.05 and $0.5 \mu \mathrm{g} / \mathrm{g}$, which are not sufficiently low to measure otolith transition and heavy metal composition accurately. Precision is $\pm 10 \%$ at 1 $\mu \mathrm{g} / \mathrm{g}$ and decreases to $\pm 30 \%$ at $0.05 \mu \mathrm{g} / \mathrm{g}$ levels. Further, quantification of trace elements, such as $\mathrm{Cd}, \mathrm{Pb}$ and $\mathrm{Zn}$ has been a persistent problem. These elements are extremely sensitive 
to any changes in laser and ICP operating conditions (Koch and Günther, 2007) because of their high volatility, low melting points, and partially different ionization potentials.

In solution-based ICP-MS analysis of otoliths, accurate measurement of trace elements and heavy metals is confounded due to overlaps from calcium and argon-based ions (e.g., ${ }^{63} \mathrm{Co}$ by ${ }^{43} \mathrm{Ca}^{16} \mathrm{O}$, ${ }^{60} \mathrm{Ni}$ by ${ }^{44} \mathrm{Ca}^{16} \mathrm{O}$, and ${ }^{56} \mathrm{Fe}$ by ${ }^{40} \mathrm{Ca}^{16} \mathrm{O}$ and ${ }^{40} \mathrm{Ar}^{16} \mathrm{O}$ ). The higher end (but typically less available) magnetic-sector ICP-MS instruments are capable of overcoming the problems associated with such spectral interferences, but there is trade-off between sensitivity (detection limit) and resolution setting. At high resolution, the limits of detection of a magnetic-sector ICP-MS are not very different from those of a quadrupole ICP-MS instrument because of loss of sensitivity (Newman, 1996). In the analysis of otoliths of juvenile halibut by high resolution ICP-MS, for instance, instrumental results were sporadic for several trace elements, including $\mathrm{Ag}, \mathrm{Al}, \mathrm{Cd}, \mathrm{Co}, \mathrm{Ni}, \mathrm{Sn}$ and $\mathrm{Zn}$, due to the detection problems, therefore, these elements were not considered in statistical evaluations (Forrester and Swearer, 2002).

Solution ICP-MS for stock identification using otolith microchemistry requires the dissolution of entire otolith, which results in the loss of the critical elemental information for the first year of life (nursery habitat) within the otolith's core. In this study, we opted for a different tack on this problem and developed a probe-based method - high resolution micromill sampling - a method that mechanically isolates otolith's core corresponding to the first year of life. A solid phase preconcentration procedure was interfaced to an ICP-MS instrument to enhance the sensitivity since high variability and inaccuracy in instrumental results for trace elements were mainly due to the lack of sensitivity as was observed in the past studies (Milton and Chenery, 2001; Forrester and Swearer, 2002). The results for the otolith CRM (Table 1) demonstrate the capability of the preconcentration ICP-MS 
methodology for measuring the elements, such as $\mathrm{Al}, \mathrm{Bi}, \mathrm{Cd}, \mathrm{Co}, \mathrm{Ga}, \mathrm{Ni}, \mathrm{Pb}$ and $\mathrm{V}$ at subng/g levels that would not otherwise be feasible with conventional ICP-MS. By means of preconcentration procedure, the limits of detection were improved by about 10 - to 15 -fold that were at least 8 times below the solution concentrations for all elements measured. For the black tuna otoliths, the masses of the cored and decontaminated otolith material ranged between 1.65 and $2.86 \mathrm{mg}$, while those of associated pair whole otoliths ranged between 12.7 and $23.8 \mathrm{mg}$. Despite an order magnitude difference in the total otolith mass, the precision achieved between paired otoliths (Fig. 6) supports the preconcentration ICP-MS analysis of isolated cores.

\section{Acknowledgements}

This research was funded a grant from the National Oceanic and Atmospheric Administration/National Marine Fisheries Service (NOAA/NMFS) (Grant No. NA16FD2290). Technical and facilities support was also provided by the NMFS Howard Marine Science Laboratory. 


\section{References}

Arai, T., Hirata, T., 2006. Determination of trace elements in otoliths of chum salmon Oncorhynchus keta by laser ablation-ICP-mass spectrometry. Fisheries Science 72, 977984.

Arai, T., Hirata, T., Takagi, Y., 2007. Application of laser ablation ICPMS to trace the environmental history of chum salmon Oncorhynchus keta. Marine Environmental Research 63, 55-66.

Arslan, Z., Paulson, A.J., 2002. Analysis of biogenic carbonates by inductively coupled plasma-mass spectrometry (ICP-MS). Flow injection on-line solid-phase preconcentration for trace element determination in fish otoliths. Analytical and Bioanalytical Chemistry 372, 776-785.

Arslan, Z., Paulson, A.J., 2003. Solid phase extraction for analysis of biogenic carbonates by electrothermal vaporization inductively coupled plasma mass spectrometry (ETV-ICPMS): an investigation of rare earth element signatures in otolith microchemistry. Analytica Chimica Acta 476, 1-13.

Arslan, Z., Secor, S.H., 2005. Analysis of trace transition elements and heavy metals in fish otoliths as tracers of habitat use by American eels in the Hudson River estuary. Estuaries 28, 382-393.

Black, B.A., Boehlert, G.W., Yoklavich, M.M., 2005. Using tree-ring crossdating techniques to validate annual growth increments in long-lived fishes. Canadian Journal of Fisheries and Aquatic Sciences 62, 2277-2284.

Campana S.E., 1999. Chemistry and composition of fish otoliths: pathways, mechanisms and applications. Marine Ecology Progress Series 188, 263-297. 
Campana, S.E., Chouinard G.A., Hanson, J.M., Fréchet, A., Brattey, J., 2000. Otolith elemental fingerprints as biological tracers of fish stocks. Fisheries Research 46, 343-357.

Campana, S.E., Chouinard, G.A., Hanson, J.M., Frechet, A., 1999. Mixing and migration of overwintering Atlantic cod (Gadus morhua) stocks near the mouth of the Gulf of St. Lawrence. Canadian Journal of Fisheries and Aquatic Sciences 56, 1873-1881.

Campana, S.E., Thorrold, S.R., 2001. Otoliths, increments, and elements: keys to a comprehensive understanding of fish populations? Canadian Journal of Fisheries and Aquatic Sciences 58, 30-38.

Edmonds, J.S., Caputi, N., Morita, M., 1991. Stock discrimination by trace element analysis of otoliths of orange roughy (Hoplostethus atlanticus), a deep-water marine teleost. Australian Journal of Marine and Freshwater Research 42, 383-389.

Edmonds, J.S., Lenanton, R.C.J., Caputi, N., Morita, M., 1992. Trace elements in the otoliths of yellow-eye mullet (Aldrichetta forsteri) as an aid to stock identification. Fisheries Research 13, 39-51.

Forrester, G.E., Swearer, S.E., 2002. Trace elements in otoliths indicate the use of open-coast versus bay nursery habitats by juvenile California halibut. Marine Ecology Progress Series 241, 201-213.

Gillanders, B. M., 2002. Connectivity between juvenile and adult fish populations: do adults remain near their recruitment estuaries? Marine Ecology Progress Series 240, 215-223.

Hoffmann, E., Lüdke, C., Scholze, H., 1997. Is laser-ablation-ICP-MS an alternative to solution analysis of solid samples? Fresenius Journal of Analytical Chemistry 359, 394398. 
Høie, H., Andersson, C., Folkvord, A., Karlsen, Ø., 2004. Precision and accuracy of stable isotope signals in otoliths of pen-reared cod (Gadus morhua) when sampled with a highresolution micromill. Marine Biology 144, 1039-1049.

Høie, H., Folkvord, A., 2006. Estimating the timing of growth rings in Atlantic cod otoliths using stable oxygen isotopes. Journal of Fish Biology 68, 826-837.

Kalish, J.M., 1993 Pre- and post-bomb radiocarbon in fish otoliths. Earth and Planetary Science Letters 114, 549-554.

Koch, J., Günther, D., 2007. Femtosecond laser ablation inductively coupled plasma mass spectrometry: achievements and remaining problems. Analytical and Bioanalytical Chemistry 387, 149-153.

Kraus, R.T., Secor, D.H., 2005. A test of the nursery-role hypothesis. Marine Ecology Progress Series 291, 301-305.

Milton, D.A., Chenery, S.R., 2001. Sources of uptake of trace metals in otoliths of juvenile barramundi (Lates calcarifer). Journal of Experimental Marine Biology and Ecology 264, 47-65.

Newman, A., 1996. Elements of ICPMS. Analytical Chemistry 68, 46A-51A.

Patterson, H.M., McBride, R.S., Julien, N., 2004, Population structure of red drum (Sciaenops ocellatus) as determined by otolith chemistry. Marine Biology 144, 855-862.

Proctor, C.H., Thresher, R.E., Gunn, J.S., Mills, D.J., Harrowfield, I.R., Sie, S.H., 1995.

Stock structure of the southern bluefin tuna Thunnus maccoyii: an investigation based on probe microanalysis of otolith composition. Marine Biology 122, 511-526.

Rooker, J.R., Secor, D.H., Zdanowicz, V.S., DeMetrio, G., Relini, L.O., 2003. Identification of northern bluefin tuna stocks from putative nurseries in the Mediterranean Sea and western Atlantic Ocean using otolith chemistry. Fisheries Oceanography 12, 75-84. 
Rooker, J.R., Secor, D.H., 2004. Stock structure and mixing of Atlantic bluefin tuna: evidence from stable $\delta^{13} \mathrm{C}$ and $\delta^{18} \mathrm{O}$ isotopes in otoliths. Collected Volumes of Scientific Papers ICCAT 56, 1115-1120.

Secor, D.H. 2004. Fish migration and the unit stock: three formative debates. In: Cadrin, S.X., Friedland, K.D., Waldman, J.R. (eds), Stock Identification Methods. Elsevier, Burlington. pp. 17-44.

Secor, D.H., Piccoli, P.M., 1996. Age- and sex-dependent migrations of striped bass in the Hudson River as determined by chemical microanalysis of otoliths. Estuaries 19, 778793.

Secor, D.H., Zdanowicz, V.S., 1998. Otolith microconstituent analysis of juvenile bluefin tuna (Thunnus thynnus) from the Mediterranean Sea and Pacific Ocean. Fisheries Research, 36, 251-256.

Secor, D.H., Rooker, J.R., Zlokovitz, E., Zdanowicz, V.S., 2001. Identification of riverine, estuarine, and coastal contingents of Hudson River striped bass based upon otolith elemental fingerprints. Marine Ecology Progress Series 211, 245-253.

Secor, D.H., Campana, S.E., Zdanowicz, V.S., Lam, J.W.H., McLaren, J.W., Rooker, J.R., 2002. Inter-laboratory comparison of Atlantic and Mediterranean bluefin tuna otolith microconstituents. ICES Journal of Marine Science 59, 1294-1304.

Swan, S.C., Geffen, A.J., Morales-Nin, B., Gordon, J.D.M., Shimmield, T., Sawyer, T., Massuti, E., 2006. Otolith chemistry: an aid to stock separation of Helicolenus dactylopterus (bluemouth) and Merluccius merluccius (European hake) in the Northeast Atlantic and Mediterranean. ICES Journal of Marine Science 63, 504-513.

Thresher, R.E., 1999. Elemental composition of otoliths as a stock delineator in fishes. Fisheries Research 43, 165-204. 
Thorrold, S.R., Latkoczy, C., Swart, P.K., Jones, C.M., 2001. Natal homing in a marine fish metapopulation. Science 291, 297-299.

Willie, S.N., Lam, J.W.H., Yang, L., Tao, G., 2001. On-line removal of Ca, Na and Mg from iminodiacetate resin for the determination of trace elements in seawater and fish otoliths by flow injection ICP-MS. Analytica Chimica Acta 447, 143-152.

Wurster, C.M., Patterson, W.P., Cheatham, M.M., 1999. Advances in microdrilling techniques: a new apparatus for acquiring high resolution oxygen and carbon stable isotope values and major/minor elemental ratios from accretionary carbonate. Computational Geosciences 25, 1159-1166.

Yoshinaga, J., Morita, M., Edmonds, J.S., 1999. Determination of copper, zinc, cadmium and lead in a fish otolith certified reference material by isotope dilution inductively coupled plasma mass spectrometry using off-line solvent extraction. Journal of Analytical Atomic Spectrometry 14, 1589-1592. 


\section{Captions for Figures}

Fig.1. Isolation of core material in blackfin tuna otolith. Shown in left panel is medial wing in sectioned sagittal otolith. The dashed line indicates target region to be isolated. Right panel shows isolated core region following micro-milling procedure. Note that "moat" surrounding core section is $\sim 2 \mathrm{~mm}$ deep. The otolith has been stained to better show micromilling result.

Fig. 2. Experimental design to test the effects of micromilling protocols on paired blackfin tuna otoliths. One otolith served as control and the other as a treatment, thus blocking for variation among fish.

Fig. 3. A: Box whisker plots for otolith metal concentrations of yearling blackfin tuna. B: Box whisker plots of proportional differences between right and left yearling blackfin tuna sagittal otolith pairs that had been decontaminated in the same manner. No bias was observed between right and left otoliths in this trial.

Fig. 4. A: Box whisker plots of proportional differences between right and left yearling blackfin tuna sagittal otolith pairs, one of which had been sectioned, but not decontaminated. B: Proportional differences between right and left yearling blackfin tuna sagittal otolith pairs, one of which had been sectioned and subsequently decontaminated. \% Difference was 
estimated as the difference divided by the control otolith; positive difference indicates significant contamination associated with the procedure.

Fig. 5. Box whisker plots of proportional differences between right and left yearling blackfin tuna sagittal otolith pairs, one of which had been embedded, but not decontaminated. \% Difference was estimated for only those elements showing significant contamination as the difference divided by the concentration of the control otolith; positive difference indicates significant contamination associated with the procedure.

Fig. 6. A: Box whisker plots of proportional differences between right and left yearling blackfin tuna sagittal otolith pairs, one of which had been sectioned, embedded and cored, but not decontaminated. B: Proportional differences between right and left yearling blackfin tuna sagittal otolith pairs, one of which had been sectioned, embedded, cored and subsequently decontaminated. \% Difference was estimated for only those elements showing significant contamination as the difference divided by the concentration of the control otolith; positive difference indicates contamination associated with the procedures. Above each bar is mean bias. 

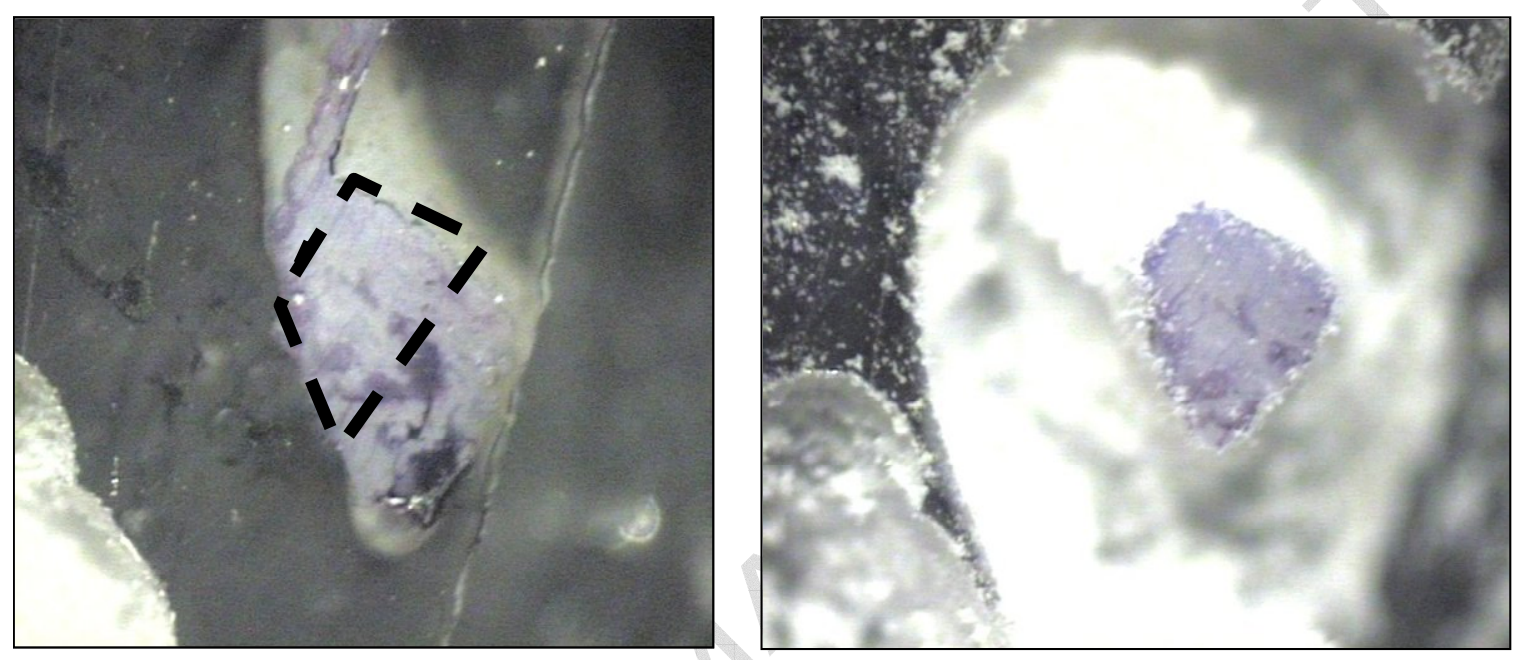

FIGURE 1 


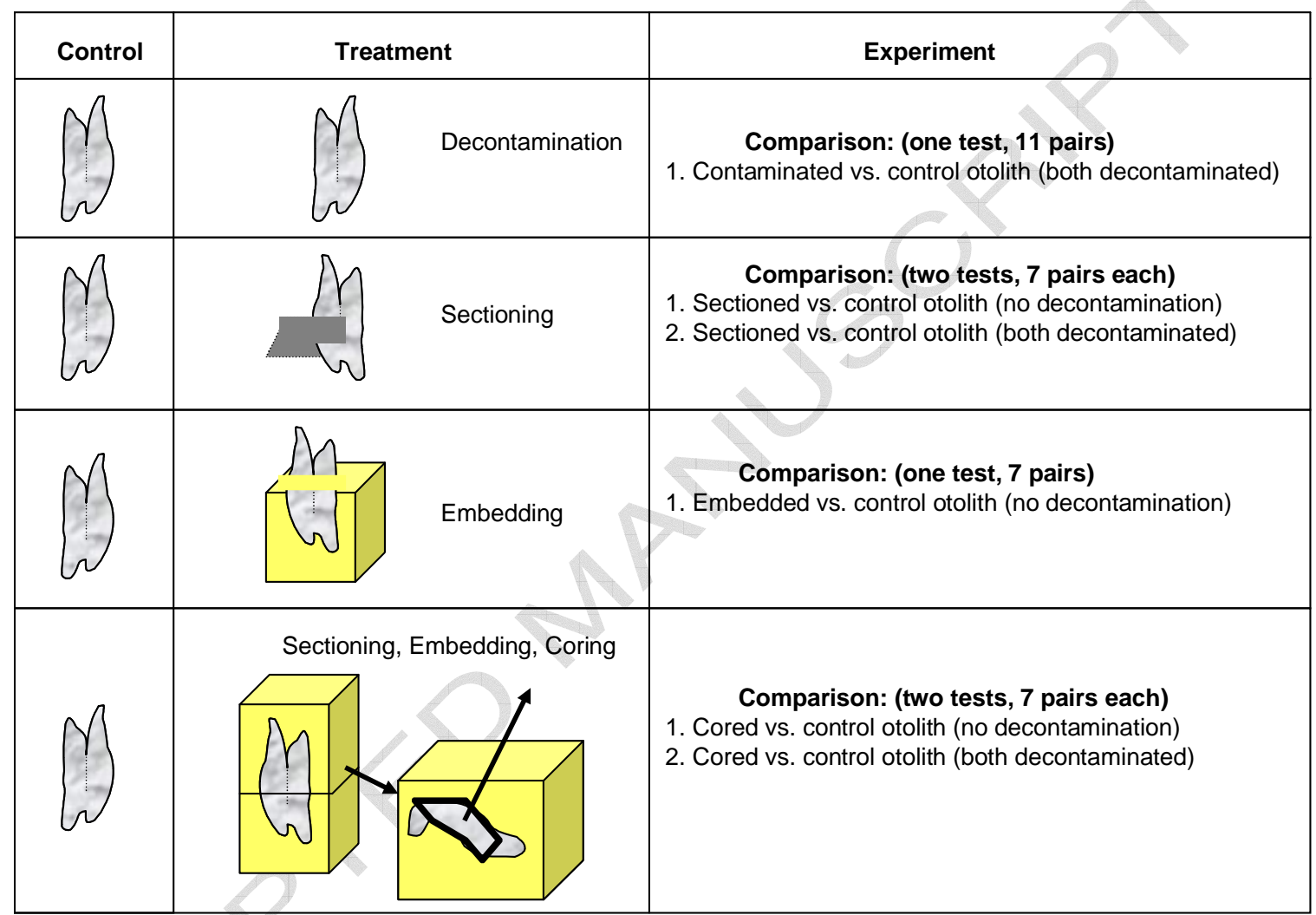

\section{FIGURE 2}



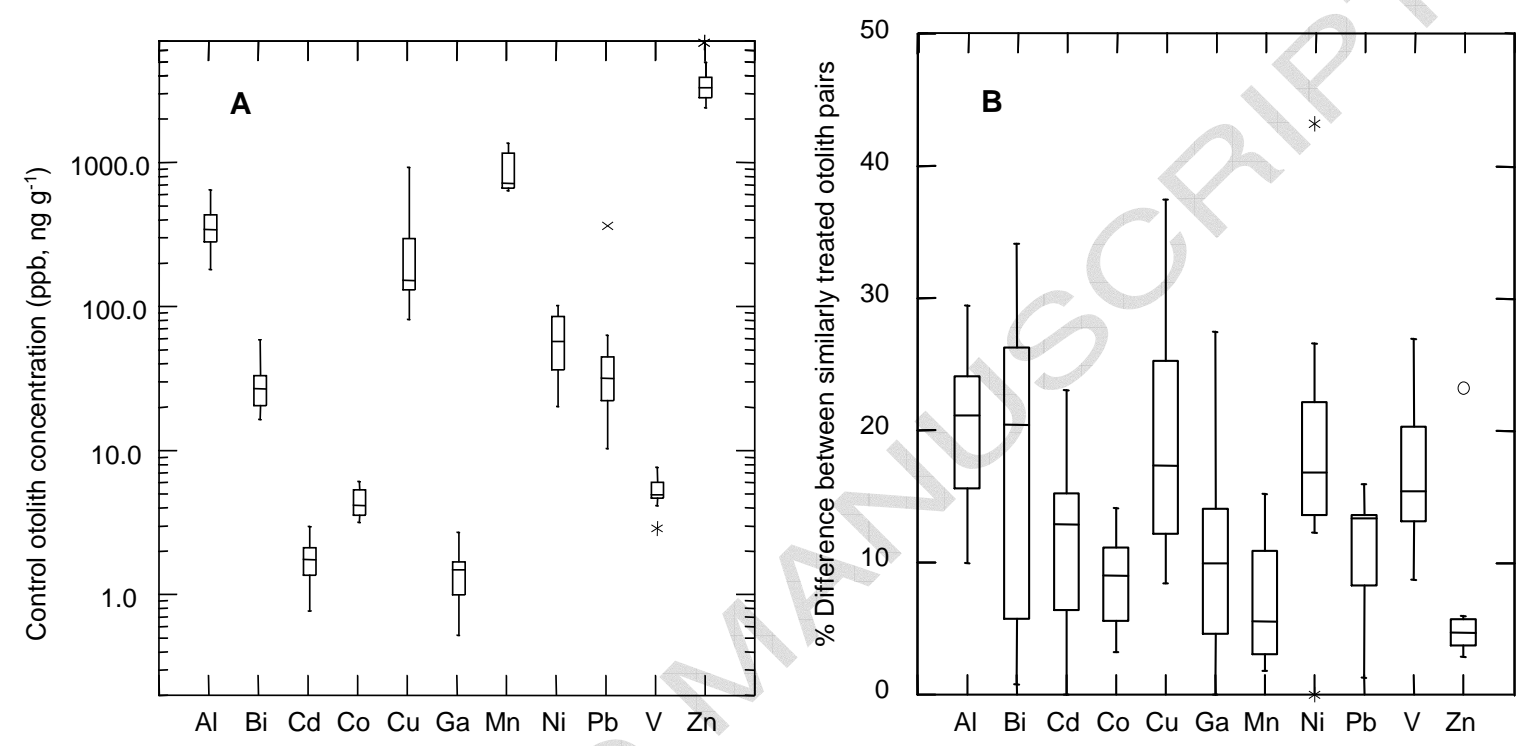

\section{FIGURE 3}



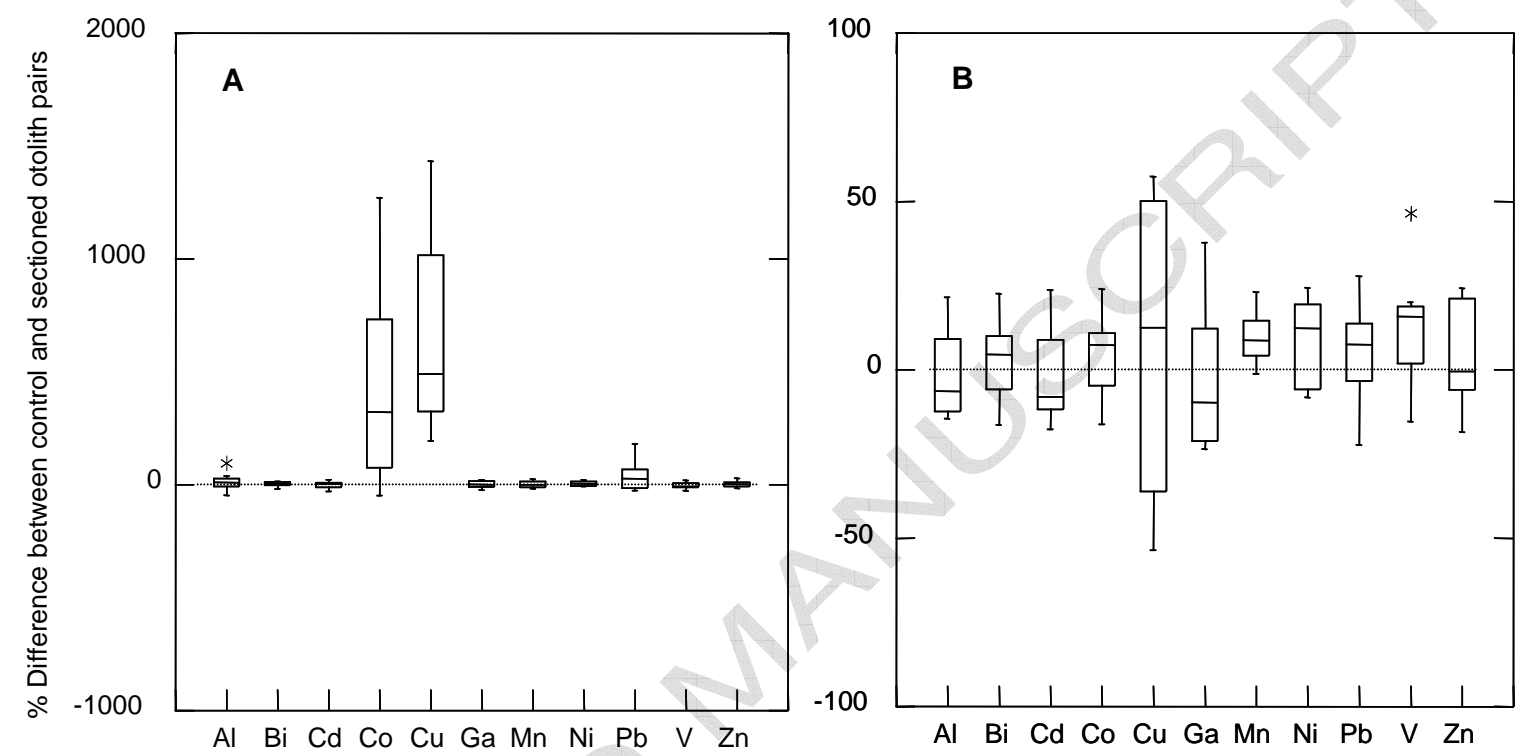

\section{FIGURE 4}




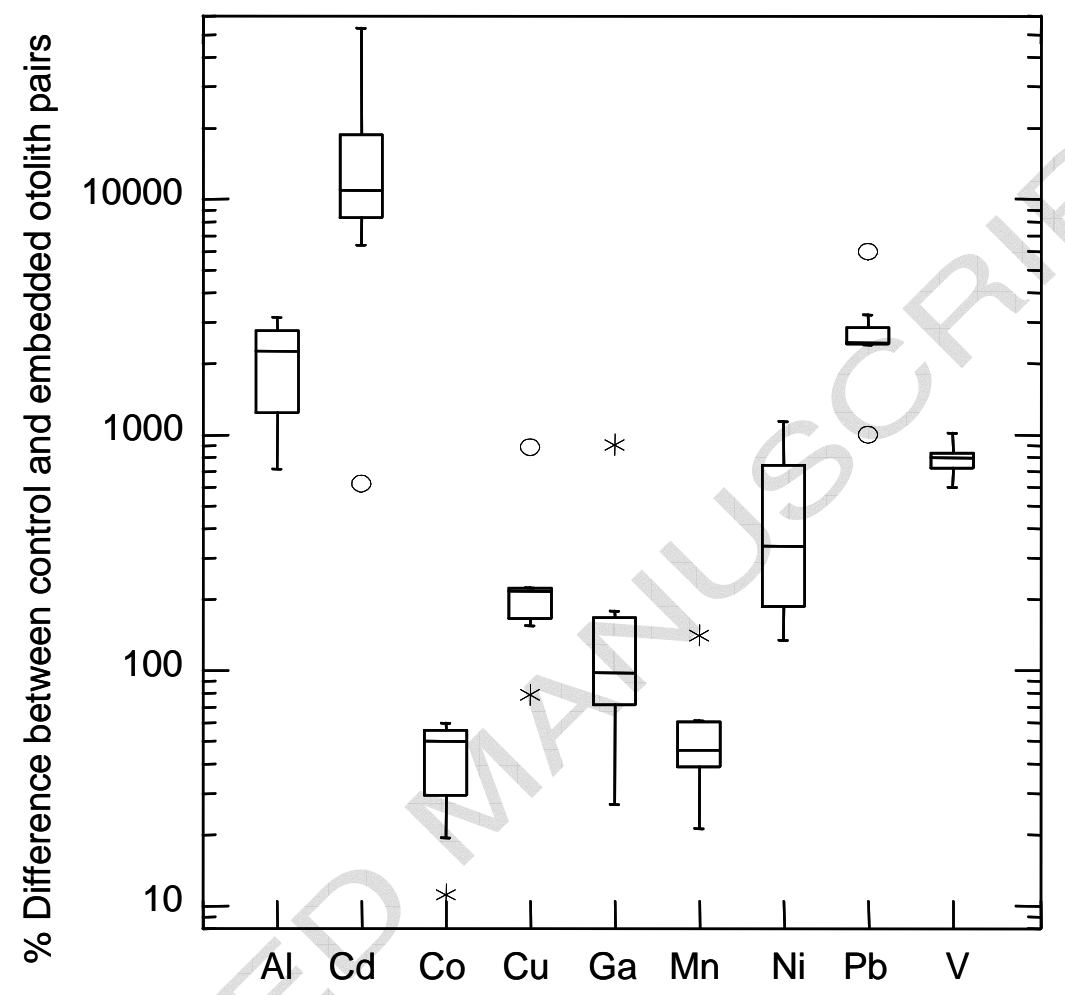

FIGURE 5 

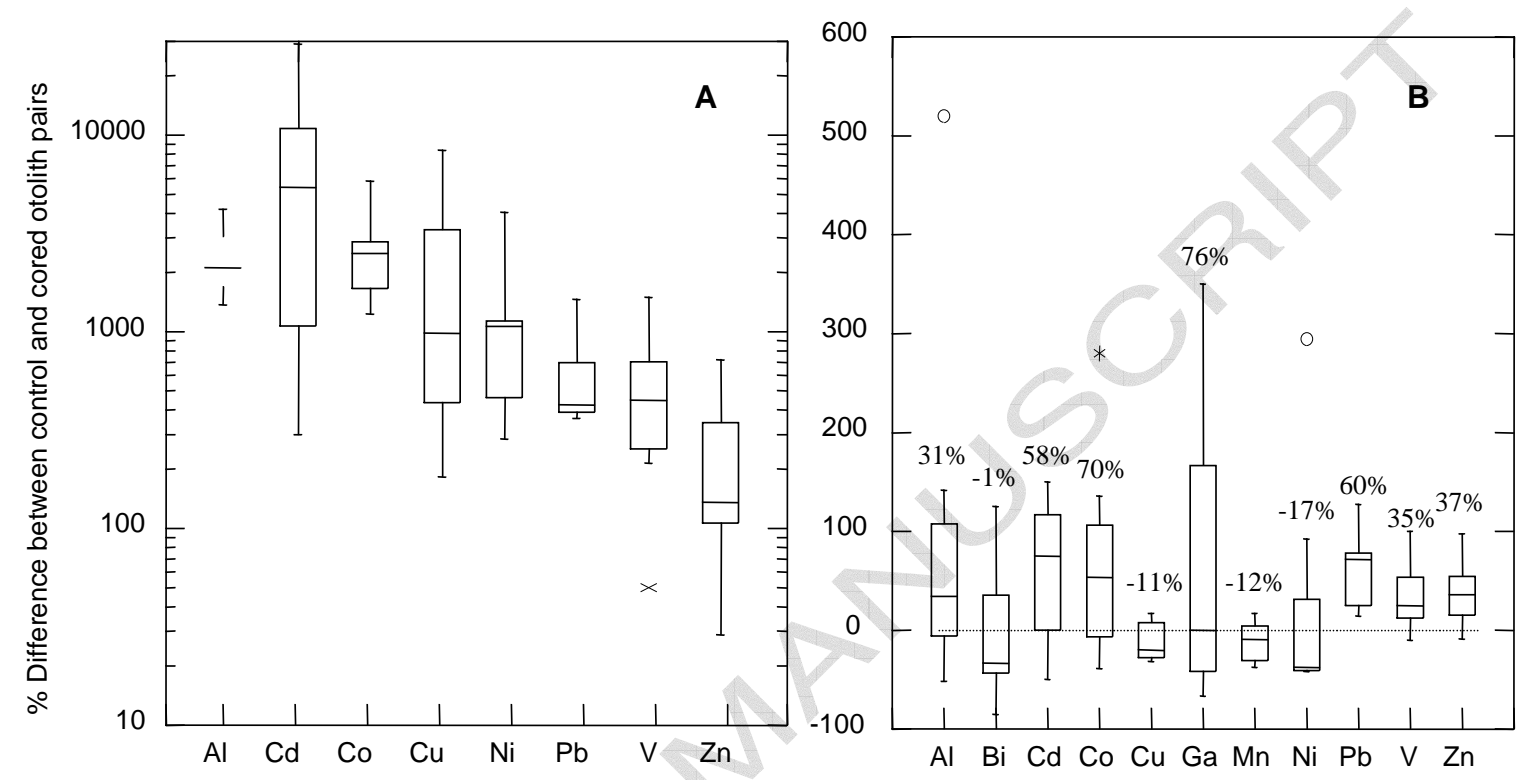

FIGURE 6 
ACCEPTED MANUSCRIPT

Table 1

Elan 5000 ICP-MS operating conditions for preconcentration analysis

\begin{tabular}{ll}
\hline RF power & $1.1 \mathrm{~kW}$ \\
Plasma gas flow rate & $15.0 \mathrm{~L} / \mathrm{min}$ \\
Nebulizer gas flow rate & $0.96 \mathrm{~L} / \mathrm{min}$ \\
Auxiliary gas flow rate & $0.80 \mathrm{~L} / \mathrm{min}$ \\
Scanning mode & Peak Hop Transient \\
Dwell time, & $50 \mathrm{~ms}$ \\
Sweeps/Reading & 1 \\
Readings/Replicate & Variable \\
Number of replicates & 3 \\
\hline
\end{tabular}


Table 2

Detection limits and results for fish otolith CRM by preconcentration ICP-MS analysis. Values are Mean \pm SD for five replicate analyses. (Ref. 1: Arslan and Paulson, 2002; Indicative value: Yoshinaga et al., 1999).

\begin{tabular}{|c|c|c|c|c|c|}
\hline \multirow[t]{2}{*}{ Element } & \multirow[t]{2}{*}{ Isotope } & \multirow[t]{2}{*}{$\begin{array}{l}\text { Detection limit } \\
\text { (ng/g) }\end{array}$} & \multicolumn{3}{|c|}{$\begin{array}{c}\text { Concentration } \\
\text { (ng/g) }\end{array}$} \\
\hline & & & This study & Ref. 1 & Indicative value \\
\hline $\mathrm{Al}$ & 27 & 4.9 & $32 \pm 3$ & $25 \pm 3$ & - \\
\hline $\mathrm{Bi}$ & 209 & 1.4 & $26 \pm 6$ & $23 \pm 2$ & - \\
\hline Cd & 114 & 0.28 & $2.5 \pm 0.5$ & $3.0 \pm 0.4$ & $2.8 \pm 0.2$ \\
\hline Co & 59 & 0.21 & $3.2 \pm 0.4$ & $2.8 \pm 0.8$ & - \\
\hline $\mathrm{Cu}$ & 63 & 2.5 & $660 \pm 42$ & $671 \pm 52$ & $742 \pm 7$ \\
\hline Ga & 71 & 0.61 & $1.4 \pm 0.3$ & $1.4 \pm 0.2$ & - \\
\hline $\mathrm{Mn}$ & 55 & 1.1 & $54 \pm 11$ & $43 \pm 8$ & - \\
\hline $\mathrm{Ni}$ & 62 & 2.1 & $23 \pm 4$ & $19 \pm 1$ & - \\
\hline $\mathrm{Pb}$ & 208 & 0.70 & $29 \pm 3$ & $26 \pm 1$ & $23 \pm 3$ \\
\hline V & 51 & 0.28 & $0.95 \pm 0.2$ & $1.0 \pm 0.1$ & - \\
\hline $\mathrm{Zn}$ & 66 & 7.4 & $449 \pm 24$ & $448 \pm 69$ & $471 \pm 2$ \\
\hline
\end{tabular}

